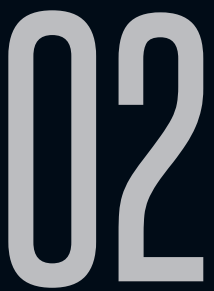

\title{
MURILO RUBIÃO: O ESCREVER, O REESCREVER E O PRAZER
}

Audemaro Taranto Goulart (PUC - MG)

Recebido em 05 jul 2020. Aprovado em 14 set 2020.
Audemaro Taranto Goulart é Professor titular na PUC-MG. Doutor pela USP (1993). Autor de variados artigos, capítulos de livros e de livro sobre a obra de Murilo Rubião, organizador de números temáticos sobre o tema, orientador de pesquisas de mestrado e doutorado versando sobre o autor e sua obra.

Resumo: Este texto intenta focalizar a obra de Murilo Rubião, considerando dois aspectos: sua opção pelo fantástico e a obsessão em reescrever continuamente seus contos. A preferência pelo fantástico é uma forma de tornar mais clara nossa visão de mundo, sobretudo do mundo que se faz opressor. A reescrita dos textos resulta de uma ânsia de perfeccionismo. Entretanto, esta compulsão leva o escritor a uma condição de sofrimento, porque como ele diz, é angustiante escrever, cortar, reescrever, corrigir e assim por diante. Para encontrar uma razão para os dois aspectos, foram consideradas as reflexões de notáveis teóricos como Wittgenstein, Freud e Norman Brown. A conclusão é de que o escrever que subjaz ao trabalho de Rubião caracteriza-se como um ato de prazer. Assim, o escritor estaria desenvolvendo um processo de superar, prazerosamente, os desequilíbrios que o mundo maquinizado impõe ao homem contemporâneo.

Palavras-chave: Murilo Rubião; Conto brasileiro; Fantástico; Reescrita; Perfeccionismo. 


\begin{abstract}
This text aims at focusing Murilo Rubião's work, considering two aspects: the writer's option for the fantastic and the obsession to continually rewrite his stories. The preference for the fantastic is a way to make our worldview clearer, especially the oppressive world. The rewriting of the texts results from a desire for perfectionism. However, this compulsion leads the writer to a condition of suffering, because as he says, it is distressing to write, cut, rewrite, correct and so on. In order to find a reason for both aspects, the reflections of notable theorists such as Wittgenstein, Freud and Norman Brown were considered. The conclusion is that the writing that underlies Rubião's work is characterized as an act of pleasure. Thus, the writer would be developing a process to overcome, happily, the imbalances that the machined world imposes on contemporary man.
\end{abstract}

Keywords: Murilo Rubião; Brazilian short story; Fantastic; Rewritten; Perfectionism.

Por que insistimos em ler a obra de Murilo Rubião? No ímpeto de uma primeira resposta, diria que ler Murilo Rubião é preciso; navegar nem tanto. Mas a resposta pode aprofundar-se em níveis mais verticais se refletirmos sobre a questão do conhecimento. Aí toca-se decisivamente na nossa angústia existencial decorrente da constatação de que nosso conhecimento é precário, absolutamente insuficiente até mesmo para que possamos responder àquela enigmática pergunta do "quem sou eu?", questão que anda no mesmo caminho daquele famoso "só sei que nada sei", atribuído a Sócrates.

Diante desse cenário, uma pergunta impõe-se de forma radical: qual é o propósito da vida? Sem dúvida, a pergunta colocanos diante da angustiante questão da carência do conhecimento, 
carência que se mostra com toda força na fragilidade do nosso saber. O homem pouco sabe de si, do outro e, sobretudo, pouco sabe da vida, pelo fato mesmo de que a vida está marcada num finalismo absolutamente incompreensível. Afinal, para que se nasce se, inevitavelmente, vai-se morrer. Esse é o ônus que nos aflige, sobretudo porque o conhecimento disponível não nos permite compreender esse enigma do nascer para a morte.

Entretanto, apesar de tudo, navegamos, ou melhor, vivemos, justamente porque dispomos de mecanismos que nos ajudam a enfrentar o desconforto de um não-saber que nos fragiliza. Tais mecanismos podem ser assim sumariados:

A ciência nos seduz com a demonstração de que caminha para promover a nossa redenção, acenando-nos com a possibilidade do prolongamento, cada vez maior, de nossas vidas, numa espécie de evolução que teria como meta alcançar a eternidade.

O mito, uma narrativa de tempos imemoriais, manifesta-se numa formulação discursiva que tem como objetivo oferecer-se como uma forma que organiza o caos. Nesse sentido, ele sempre funcionará como um mecanismo que alivia as tensões justamente porque desvia o fluxo de uma irrupção incontrolável, minimizando seus efeitos e tornando as tensões angustiantes mais fáceis de serem aceitas.

Os credos religiosos procuram estabilizar as emoções, mostrando que a provisoriedade de nossa vida nada mais é que um momento de passagem para uma vida eterna redentora.

A arte trabalha no sentido de tomar os elementos em desequilíbrio nas relações conflitantes, para articulá-los de forma 
a mostrar caminhos e experiências que operam, no mínimo, a condição de propiciar uma forma de saber que são as condições de aprendermos a conviver com o não sabido.

Vamos nos deter na questão da arte, onde se situa o texto literário, para chegarmos ao nosso Murilo Rubião. E aí dois movimentos da obra de Murilo merecem uma boa dose de reflexão: a opção pelo fantástico e a obsessão do autor em reescrever freneticamente seus textos a cada republicação.

Diga-se, a título de introdução do assunto, que é muito grande o número de autores e obras que teorizaram sobre o fantástico, começando com o russo Vladimir Soloviov, o inglês Montague Rhodes James e a alemã Olga Reimann. Desde então, muitas reflexões foram produzidas sobre o tema, destacando-se nomes como o de Todorov - mais importante pelo seu levantamento histórico que propriamente por suas posições teóricas - Roger Caillois, Pierre-Georges Castex e Irène Bessiére. Também escritores que cultivaram o gênero sempre se manifestaram sobre a natureza da obra fantástica como o caso de Jorge Luís Borges, Ernst Hoffmann, Edgar Allan Poe, o que faz do fantástico um dos movimentos mais discutidos nos dois últimos séculos.

Houvesse tempo, seria produtivo discutir aqui o que identifica - fantástico, sobretudo para tentar diferenciá-lo do realismo mágico, gênero com a qual mantém um íntimo parentesco mas que também dele se afasta nas suas principais linhas de força. Dessa maneira, vamos nos deter no que representa o caráter da obra fantástica de Murilo Rubião, lembrando, logo de início, que a obra muriliana publicada em livro está toda enfeixada no plano 
da subversão do real, projetando uma dimensão surrealizante muito próxima do modelo kafkiano. Isso, inclusive, tem suscitado a constante indagação que quer saber se Murilo Rubião não teria se espelhado no autor tcheco para escrever seus contos. Murilo, mais de uma vez, fez questão de dizer que só veio a conhecer Kafka depois que já havia produzido um considerável repertório de seus contos. A questão, aliás, não é relevante, pois o que importa realmente é o fato de que a obra de Murilo é única e original, devido às suas características e pela sua fidelidade a um modelo de fantástico que nunca quis abrir espaços significativos ao real conhecido.

O fantástico em Murilo ocorre no plano de Kafka e de Cortázar e, ainda mais significativamente que na obra desses escritores, investe contra o racionalismo, pondo em xeque os pressupostos consagrados da filosofia e, por essa via, da cultura. Na verdade, a obra muriliana surpreende e, em cada página, põe em suspenso o conforto de uma leitura fluviante e descomprometida, mostrando que é preciso atacar a tradicional figuração do mundo real, justamente para que se aprenda a enxergar melhor o mundo em que se vive.

Neste ponto, destaco os versos do poeta colombiano, Germán Pardo García, quando diz: "He llegado a ese límite en que el mundo se agranda más y más y necessito de otros ojos inmensos para verle y de otro corazón para sentirlo". Os versos dão bem a medida do que pode representar o exagero de fatos e de situações que parecem entrar em colisão com o real cotidiano. Na verdade, o mundo da racionalidade hipertrofiada, resultante, sobretudo, da imposição de uma razão instrumental, está cheio 
de acontecimentos absurdos e insólitos. Basta ver o que acontece diariamente diante de nossos olhos e do que ouvimos ou lemos na mídia. Para não se falar nas calamitosas ações dos criminosos comuns ou dos que se agrupam no crime organizado, temos ocorrências chocantes praticadas pelo cidadão comum, sobretudo aqueles que agem sob o exacerbamento de instintos reprimidos que são uma herança do nosso passado animal. Mas tudo isso se dá como se fossem ações comuns, conhecidas e, portanto, compreensíveis. Nesse cenário a violência é, na maioria das vezes, absurda e chocante mas a banalização dessa violência se insere no mundo cotidiano, neutralizando a indignação e a reação que deveriam confrontá-la. Em suma, acostumamo-nos a viver num mundo de sobressaltos e de crueldade, enxergando tudo sob a óptica de um mundo que, apesar de tudo, é o nosso mundo real.

É por isso que se pode dizer que, hoje, vive-se uma realidade espetacularizada cujos efeitos representam um processo de alienação dos indivíduos que passam a transitar no mundo como se estivessem anestesiados, sem sofrerem os impactos das agressões que sacodem a vida de todos. E essa acomodação compulsória já de há muito vem imprimindo nos seres as marcas de uma automatização que só faz afastá-los dos avatares de sua condição humana.

É aí que o universo do fantástico, explicitando uma realidade insólita e anormal, pode interpor uma interrogação e uma advertência, como que anunciando que é preciso abrir os olhos para poder enxergar melhor. Como disse o poeta colombiano, o mundo vem se tornando tão grande e surpreendente que necessitamos de olhos imensos para vê-lo e de um outro coração 
para senti-lo. Os contos de Murilo Rubião são, nesse sentido, um exercício permanente de uma melhor compreensão do que nos rodeia e nos oprime. E uma ação precisa é quando Murilo põe em cena o homem emparedado, o ser que sucumbe às forças que estão a sua volta, destinados a um improvável dia seguinte. A título de exemplo, vou citar três contos que dão uma ideia de como a realidade mostrada na obra de Rubião é um irreversível beco sem saída.

Veja-se a situação de João Gaspar, personagem de "O edifício", engenheiro encarregado de gerir a construção do maior arranha-céu de que se tinha notícia e que depois de erguer o prédio a uma altura superior a 800 andares acaba perdendo inteiramente o domínio sobre os operários e sobre a própria construção. Determinado a pôr um fim às obras, o engenheiro vê, assombrado e vencido, que os operários recusam-se a atendê-lo e, continuando a trabalhar, fazem com que o edifício continue a subir indefinidamente.

Também Gérion, personagem de "O bloqueio", vê-se ilhado num andar do prédio onde morava. Só que essa condição ocorre diante da inusitada situação de perceber que seu andar como que flutuava no ar, pois era o único que restara do trabalho de demolição do seu prédio.

O marido de Bárbara, protagonista do conto de mesmo nome, é um condenado a fazer milagres para atender aos absurdos e compulsivos desejos da mulher. Por mais que tente, ele não consegue desvencilhar-se desse destino opressor, como mostra o final da narrativa em que Bárbara passa longo tempo olhando 
fixamente o céu. É um alívio para o narrador-personagem quando Ihe vem mais um pedido: a mulher não queria a lua, mas uma minúscula estrela quase invisível a seu lado. E ele, com esse conforto, vai buscá-la.

Alexandre Saldanha Ribeiro, personagem de "A armadilha", é outro emparedado completamente submetido por um velho, antigo conhecido que o esperava, há dois anos, sentado numa cadeira na sala do apartamento para onde Saldanha fora. Poucas indicações há para explicar o que levara o velho a proceder daquela forma. $\mathrm{O}$ certo é que a armadilha fora montada e agora era irreversível. Com as janelas gradeadas e uma porta de aço intransponível, Alexandre Saldanha ouve aterrorizado a sentença que o aniquila como um emparedado sem saída: "Aqui ficaremos: um ano, dez, cem ou mil anos".

No conto "A fila", Pererico vem do interior para uma entrevista com o diretor de uma empresa. Sofre todo tipo de obstáculos colocados por um indivíduo destacado para controlar uma fila enorme de outros interessados em falar com o diretor. Passa meses tentando a entrevista até que, desanimado, passa a viver às expensas de uma prostituta, deixando de comparecer diariamente na fábrica, como fazia antes. Certo dia, volta para mais uma tentativa, quando fica sabendo que o diretor morrera. Pergunta, então, ao atendente se muitos tinham ficado sem falar com ele. A resposta é arrasadora para Pererico: "Somente você. Nas duas últimas semanas, prevendo a proximidade da morte, atendeu a todos que apareceram". A fila interminável é o instrumento que empareda a personagem. 
Aliás, é de extrema importância esse abrir de olhos que o fantástico muriliano propicia no sentido de sugerir-nos uma visão mais crítica sobre os fatos e acontecimentos que nos rodeiam. Aliada à dimensão do trágico que também percorre a obra de Rubião, a visão do fantástico quer chamar a atenção para o que existe mas é pouco percebido pelas nossas retinas tão fatigadas, como diria o poeta.

Quanto ao segundo movimento que estou destacando na obra de Murilo Rubião - o vezo de reescrever os contos a cada nova publicação - seria importante destacar um outro aspecto insólito. Murilo publicou, ao longo de sua vida, sete livros. Desses, apenas três são inteiramente inéditos: o primeiro livro, de 1947, 0 exmágico (com 15 contos), o segundo, de 1953, A estrela vermelha (com 4 contos) e o quarto livro, de 1974, O convidado (com 9 contos). O terceiro livro, Os dragões e outros contos, de 1965, traz vinte contos, sendo que apenas quatro são inéditos, uma vez que doze deles são republicações do primeiro livro e quatro outros vieram do segundo livro.

Nesse painel, verifica-se que dos 112 contos publicados, nada menos que 80 são republicações. Aliás, é preciso acrescentar mais um outro conto. Trata-se de "A diáspora", narrativa que foi perdida por Murilo num táxi e que só se recuperou muito tempo depois. Assim, os números reais são: 113 contos publicados, dos quais 33 são inéditos.

As explicações para esses números tão surpreendentes não faltam, a começar pela que fala numa compulsão de perfeccionismo que sempre acompanhou o escritor. 0 perfeccionista nunca 
está satisfeito, razão pela qual, no caso de um escritor, sempre estará trabalhando e retrabalhando seus textos em busca de um resultado inalcançável mas sempre idealizado. Essa busca de uma obra concebida segundo um modelo irretocável é que levou Murilo Rubião a considerar a literatura como uma maldição. De acordo com suas palavras, ele só tinha um efetivo prazer quando estava compondo o conto. Depois era aquele sofrimento de rever, cortar, corrigir, acrescentar, modificar. E em todas as vezes que Murilo republicou um conto, modificações foram feitas. Assim, no caso do conto "O ex-mágico da taberna minhota", republicado quatro vezes, vão-se perceber modificações em todos os textos. A perfeição não existe, mas ela deve sempre ser buscada, é o que imanta o espírito dos perfeccionistas.

Mas podem-se buscar outras justificativas que falem desse criador que jamais se dá por satisfeito. Trata-se de algo que está no plano de mecanismos psicológicos sutis que interveem na produção do texto literário e que devem ser considerados de uma perspectiva mais vertical.

Em primeiro lugar, seria importante levar em consideração o fato de que muitos escritores escrevem atendendo a uma compulsão que funciona como forma de lidar com passagens angustiantes de suas vidas. Lembraria alguns exemplos de autores consagrados que viram na escrita um modo de enfrentar a perda de entes queridos, como é o caso de Carlos Drummond de Andrade que escreveu vários textos falando da morte de sua filha Maria Julieta, de Machado de Assis, com seu poema "A Carolina", sua melhor produção lírica, dedicado a sua mulher Carolina Novais, de Fagundes Varela, ao escrever "Cântico do Calvário", em lembrança 
do filho, prematuramente falecido, de Manuel Bandeira, com vários poemas com que enfrentou o pesadelo da morte que o acometeu ainda jovem, de Eric Clapton, astro pop britânico, com seu "Tears in heaven", composto em homenagem ao filho morto aos quatro anos de idade. Tais exemplos revelam com propriedade o caráter singular da escrita enquanto mecanismo restaurador de um equilíbrio comprometido.

Essa condição representa bem aquela forma de restaurar o equilíbrio das relações conflitantes, tal como colocado por Schiller ao falar da estética enquanto componente da arte na promoção de uma harmonia emocional do sujeito. As reflexões de Schiller representam uma notável contribuição para os estudos da estética como atesta sua obra Cartas sobre a educação estética da humanidade (2a. ed. de 1992), também chamada de A educação estética do homem, numa publicação de outra editora em 2002. No seu texto, Schiller revela uma significativa pesquisa sobre o assunto, sobretudo da magna obra de Kant, Crítica do juízo, oferecendo, em linhas gerais, reflexões que vão indicar a estética como um movimento que procura equilibrar elementos conflitantes como emoção e razão, natureza e tecnologia, elementos que são jogados nas relações humanas, cobrando do homem um elevado preço por sua alienação ao sedutor canto da ciência, renunciando a grande parte de sua condição humana, justamente aquela que o liga a um modo de vida que deveria ter mais consonância com a natureza.

Muito haveria a refletir sobre o tema mas vamos nos limitar a algumas poucas indicações que jogam luz sobre a questão da linguagem (ou da escrita) como componente precioso para o estabelecimento dos princípios estéticos enquanto modo de 
operar o equilíbrio comprometido na condição humana. Assim, lembre-se que Schiller fala de dois impulsos fundamentais da natureza do homem: a tensão e a distensão. As forças sensíveis e as forças espirituais do homem precisam situar-se no nível do que se pode chamar de energia concordante. $\mathrm{O}$ desequilíbrio dessa harmonização de energia compromete o que seria o homem ideal, pois vai comprometer o equilíbrio das forças sensíveis e espirituais. Assim, se falta harmonia, o sujeito é invadido pela tensão; de outro lado, se Ihe falta energia ele se deixa dominar por uma debilidade que o torna frouxo. É nesse plano que entra a estética, caracterizada como manifestação da beleza, que restaurará o equilíbrio, na medida em que produzirá no homem tenso a harmonia e no homem enfraquecido, lasso, a energia faltante. Essa dimensão da harmonia é a principal linha de força da estética segundo as colocações de Schiller.

Desse modo, pode-se perceber que a compulsão de Murilo para escrever, reescrever e mais reescrever seus textos está intimamente ligada à busca de um equilíbrio que, no perfeccionista, está sempre balançando. Exercitar a reescrita dos contos num estado de exaltação extrema é buscar alívio, na medida em que, intimamente, o escritor está em busca de harmonia, de equilíbrio. A escrita surge assim como um modo perfeito de fazer com que o tenso se distensione, restabelecendo sua serenidade. Essa é a força do texto produzido. Esse é o seu milagre.

A essas considerações pode-se acrescentar uma outra reflexão que também oferece um caminho para explicar a compulsão que leva Murilo a escrever e, sobretudo, reescrever seus contos. Começaria lembrando as colocações de Freud, esclarecendo 
o que alimenta a criação literária. Em seu "Escritores criativos e devaneios", Freud diz que os primeiros traços da atividade imaginativa devem ser buscados na infância. A justificativa que o pai da psicanálise oferece é a de que a criança vive um mundo em que só importa o brinquedo, ou seja, uma realidade inventada em que os elementos de seu mundo são dispostos de um modo que a agrada. Freud ainda esclarece que o mundo criado pela criança não significa desconhecer o mundo real. Ela separa bem as duas situações e deriva um grande prazer em fruir o mundo inventado. 0 que se vê, pois, é que a atividade infantil é da mesma natureza que a do escritor criativo. Tudo é uma questão de invenção, de criação do imaginário.

E é aqui que surge uma observação importante feita por Freud quando aproxima o escritor criativo da criança: "O escritor criativo faz o mesmo que a criança que brinca. Cria um mundo de fantasia que ela leva muito a sério, isto é, no qual investe uma grande quantidade de emoção, enquanto mantém uma separação nítida entre o mesmo e a realidade. A linguagem preservou essa relação entre o brincar infantil e a criação poética" (1976, p.150).

Veja-se, nas palavras de Freud, a importância que ele confere à linguagem como elemento articulador entre o brincar e o criar. E isso é possível porque a linguagem é uma coisa extraordinária e, sobretudo, misteriosa. Para ilustrar a afirmação, apresento o que seria uma definição operacional de língua: 1) A língua é um conjunto constituído por um número finito de elementos: os fonemas e os morfemas. 2) Esse conjunto finito de fonemas e morfemas articula-se de acordo com um número também finito de possibilidades. 3) O resultado desse número finito de elementos combinando-se num jogo também finito 
de possibilidades oferece, surpreendentemente, um desempenho infinito, fazendo com que novas palavras e expressões surjam na língua diariamente. Como isso é possível? Mistério, enigma.

Esse mistério contorna, obviamente, a linguagem enquanto instrumento usado pelo ser humano para se comunicar, para brincar e para criar. E é por isso que a linguagem encanta e seduz. Não é por outro motivo que Wittgenstein, filósofo que tinha a genialidade de entender os segredos da linguagem, cunhou uma frase famosa: "A filosofia é uma batalha contra o enfeitiçamento de nossa inteligência através da linguagem".

Uma posição inteiramente alinhada com as colocações de Freud é a do norte-americano Norman Brown, um filósofo social que foi um profundo estudioso da obra de Freud. Em seu Vida contra a morte, Brown faz algumas reflexões que tocam de perto o que Freud colocou sobre a importância da linguagem como, por exemplo, reconhecer que a linguagem origina-se na vida das crianças a partir da brincadeiras e do amor que estão concentradas na mãe. Daí que Brown diga que "na evolução ontogenética de cada ser humano está a linguagem do amor e do princípio do prazer antes que se transforme na linguagem do trabalho e do princípio da realidade", concluindo, então, que "a linguagem é uma superestrutura operacional sobre uma base erótica", justamente porque a aquisição da capacidade da fala pela criança vai corresponder ao momento em que a sexualidade infantil desabrocha. Exatamente por desenvolver tal característica é que a linguagem caracteriza-se como uma atividade de prazer e de diversão, na medida em que o aprender a falar é para a criança um brinquedo que enriquece o seu mundo de brinquedo. 
Nas suas considerações, Norman Brown insiste em dizer que a linguagem traz consigo o pensamento como realizador de desejo, esclarecendo que tal pensamento é um legado da infância existente em todos nós, relacionado com o puro ego-prazer.

Diante das considerações feitas, pode-se propor algo como justificativa para a peculiar disposição de Murilo Rubião em escrever e reescrever, obstinadamente, os seus contos. No fundo, diferentemente do que afirmou em entrevistas, pode-se perceber que Murilo se autocomprazia em se entregar àquele trabalho de produção e reprodução, de criação e de recriação porque ali ele operava aquela energia concordante das forças sensíveis e espirituais de que nos fala Schiller, compondo um equilíbrio e uma harmonia responsáveis por uma formação conciliatória do sujeito. Essa disposição, na perspectiva de Schiller, torna a produção do texto um exercício que restaura forças e supera momentos angustiantes porque tudo está submetido ao poder misterioso e encantatório das palavras, gerando a beleza estética.

De outro lado, se lermos na pauta de Norman Brown, vamos encontrar um Murilo absorto num trabalho aparentemente exaustivo mas que era, na verdade, uma atividade prazerosa, diversória. Segundo Brown, a linguagem traz no seu bojo uma modalidade de expressão erótica, originada na infância, que depois acaba dominada pelo princípio da realidade. Isso significa que a linguagem pode, perfeitamente, manifestar aqueles ecos do erotismo, sobretudo, quando caminha na direção da criação artística, momento em que tal criação pode ser vista como sexualidade sublimada, como postulado por Freud ao caracterizar a pulsão sexual deslocada para um alvo não sexual. 
Diante de tudo isso, parece-me justo concluir que Murilo Rubião entregava-se a um trabalho árduo mas do qual, no fundo, derivava grande prazer. O suposto sofrimento era a busca da harmonia, do equilíbrio, do comprazimento de estar criando não a história, mas recriando a história através do trabalho na linguagem.

Era assim que Murilo encontrava-se consigo mesmo e tinha enorme prazer em fazê-lo. Sorte a nossa de podermos contar com esse exercício tão refinado, na medida em que coparticipamos desse trabalho de criação/recriação ofertando, como um privilégio, a nossa cota de leitores.

\section{REFERÊNCIAS}

BESSIÈRE, Irène (1974). Le récit fantastique; la poétique de I'incertain. Paris: Librairie Larousse.

BROWN, Norman (1972). Vida contra morte. Nathanael C. Caixeiro (Trad.). Petropólis: Editora Vozes Ltda,.

FREUD, Sigmund (1976). El creador literario y el fantaseo. In: El delírio y los sueños em la "Gradiva" de W. Jensen y otras obras, v. 9. Buenos Aires: Amorrortu editores S.A.

GOULART, Audemaro Taranto (1995). O conto fantástico de Murilo Rubião. Belo Horizonte: Editora Lê.

RUBIÃO, Murilo (1998). Contos reunidos. São Paulo: Ática.

SCHILLER, Friedrich (1992). Cartas sobre a educação estética da humanidade. Roberto Schwarz (Trad.). São Paulo: Editora Pedagógica Universitária Ltda. 